\title{
THE EMBEDDED TEXTBOOK: COLLABORATING WITH FACULTY TO EMPLOY LIBRARY SUBSCRIPTION E- BOOKS AS CORE COURSE TEXT
}

\section{Brooke Gilmore Ratto, Information Literacy Librarian \\ Andy Lynch, Associate Professor of Marketing \\ Southern New Hampshire University}

\begin{abstract}
.
Student and faculty frustrations with traditional higher education textbook models continue to escalate. These frustrations present an opportunity for academic libraries to forge partnerships with teaching faculty and vendors to repurpose existing library resources. Library and teaching faculty at Southern New Hampshire University collaborated to develop a textbook alternative option from subscription ebook content contained in the Books $24 \times 7$ database. This alternative consisted of a series of links embedded into the Blackboard learning-management system. This partnership provided students with significant financial relief, allowed students to experiment with using e-book content, and increased library resource awareness and use.
\end{abstract}

Keywords: Electronic books, textbooks, faculty partnerships, collaboration, vendor relations, BlackBoard

While there may be no definitive role for academic libraries in the textbook, e-textbook, or open educational resource debate, this article discusses how library and teaching faculty at Southern New Hampshire University (SNHU) collaborated to leverage existing electronic library resources to serve as the foundational "textbook" for an introductory business course. The purpose of this article is threefold: to introduce a study that measured undergraduate student perceptions of a library resourcedriven textbook alternative, to outline for the reader the steps taken by library and teaching faculty to 
produce this textbook alternative so that it can be replicated, and to emphasize the positive impact library and teaching faculty collaboration can have on student learning experiences.

The study conducted by library and business faculty provided undergraduate marketing students $(\mathrm{N}=87$ ) with three content options: traditional textbook only, embedded e-book links from the Books $24 \times 7$ database, or a combination of the two. These three options served as the foundational content for three sections of an introductory marketing course. Throughout this pilot course, faculty members monitored student feedback on their experiences using both the traditional textbook and embedded ebook link options via responses to online surveys posted on the course Blackboard site at intervals throughout the semester. Results suggest that students are not fearful of using e-books as a foundational textbook source, and that library subscription resources may be viable options for textbook alternatives or replacements. Students reported high satisfaction levels on cost savings and the convenience of using e-books. Moreover, the library experienced increased use and awareness of its Books 24x7 e-book collection.

The results of this study are important in light of the body of literature indicating that college students prefer print books and textbooks to their electronic counterparts. However, perhaps the more valuable outcome of this study is the potential benefit to students when library and teaching faculty collaborate to redefine part of the library's collection to support course curriculum and delivery.

\section{Background}

Southern New Hampshire University's Shapiro Library has actively purchased electronic book titles and collections for several years. The library acquired its first major e-book collections via netLibrary and Safari Tech Books Online subscriptions in 2003. As of July 2011, the library has catalog 
records of 17,486 unique e-book titles from these vendors, as well as Books 24x7, Credo Reference, Sage, Gale, and Infobase. Open-access titles available through the ACLS Humanities E-book Project are also included in the library's cataloged e-book collection. This robust e-book collection allows the library to meet the needs of the university's large distance and online learning populations, as well as provide on-campus students and faculty with a variety of information formats and increase the monograph collection without jeopardizing valuable floor space. Moreover, these collections demonstrate the library's effectual transition from print to electronic resource environments in the digital age.

To increase electronic resource awareness, librarians demonstrated the Books $24 \times 7$ e-book database, among others, to faculty at a training session at the end of the 2009-2010 academic year. While developing a syllabus over the following summer months for an Introduction to Marketing course, a business faculty member present for the training discovered that the Books $24 \times 7$ database contained updated and relevant content in support of all course key terms and concepts. This realization led to the following research questions: Is it possible to replace an assigned course textbook with e-book database content without losing content quality or convenience?; How can/should this content be delivered?; What variables are involved in student e-book adoption?; and what is the commitment needed of teaching faculty and librarians to successfully create and sustain this model?

\section{Literature Review}

There is much speculation in higher education regarding the demise of the print textbook (Grensing-Pophal, 2010; Nelson, 2008; Birnbaum, 2004). The cost associated with textbooks is perhaps the most obvious factor in students' dissatisfaction. The cost of the "average" college textbook (Kingsbury \& Galloway, 2006) increased 186\% between 1986 and 2004, helping annual textbook costs reach $\$ 900$ per student (Waldman, 2010). Such dramatic increases are largely due to the practice of 
"textbook bundling," or packaging the print material with multimedia supplements that may be superfluous. Yet high cost is not the only negative aspect of the traditional textbook model. Textbook publishers release new editions of titles every few years, making up-to-date materials impossible to keep up with for students, faculty, and the university library (Buczynki, 2007). Print textbooks are also notably bulky and environmentally unfriendly (Shepperd, Grace, \& Koch, 2008).

Libraries are often unsure of their role in the textbook debate. One method of dealing with the textbook dilemma has been for libraries to purchase and provide copies of required texts on reserve; this is often an ephemeral fix, as libraries do not often have the budget to supply textbooks beyond the core, required undergraduate courses. Moreover, these copies are quickly superseded by newer editions of the text, limiting their usefulness in the permanent library collection. As books (and textbooks) begin to evolve into digital formats, course reserves may no longer be a viable option (Buczynki, 2007).

One method of addressing the perceived unfair costs associated with print textbooks and the evolving learning styles of today's digital natives is to adopt library subscriptions to electronic resources, and electronic books specifically, as the course "textbook." The subject of library e-book collections and use has been prominent in the literature of the twenty-first century. While e-books may not be appropriate for all disciplines and university courses, studies have shown that the e-book model works especially well in the business disciplines (Buczynski, 2007; Jamali, Nicholas, \& Rowlands, 2009; Nicholas, Rowlands, \& Jamali, 2010; Dillon, 2001). Moreover, several studies indicate that students access and read e-books in the same manner as traditional textbooks; readers tend to "dip" in and out of sections of the text and digest information in chunked out text (Nicholas, et al., 2010; Christianson, M., 2005; Appleton, 2004). It is an easier transition for students to use an e-book like a textbook than for leisure 
reading. The challenge is not having the content available but linking faculty to these resources and encouraging them to share with students to help achieve learning goals. This is critical to note, as a 2006 study conducted at the University of Denver by Michael Levine-Clark found that students were more aware of e-book resources when directed to e-books by a librarian or professor. However, LevineClark (2006) found that "awareness of electronic book availability does not necessarily translate into use" (p. 291).

Academic librarians are well known for their ability to effectively communicate and collaborate with faculty in support of student learning. These partnerships range in level of involvement from what Pritchard (2010) defines as supplemental, integrated, and embedded models. While librarians commonly work with faculty to provide research help, build library collections, and deliver informationliteracy instruction sessions to students, these relationships are not always wholly collaborative in nature. According to Pritchard (2010), a true collaborative partnership between library and faculty members occurs when librarians are treated as partners and have a hand in course curriculum and delivery. The study documented in this article illustrates how librarians and faculty, working together in a true collaborative partnership, can contribute to the textbook solution through leveraging library subscription e-book content.

\section{Timeline for Development}

\section{Pre-Course Development}

The "pre-course" period (approximately two weeks), in this case, is the time between initial idea conception and discussion between the librarian and faculty member and the first day of the undergraduate fall semester 2010. During this time, the authors made major decisions regarding content and delivery. As previously mentioned, the librarian-faculty team chose the Books $24 \times 7$ 
database as the e-book content source due to the 1,284 relevant titles and chapters that covered the key terms and concepts students were responsible for learning in the course. Books $24 \times 7$ is also a viable database for this model because it does not have limits on simultaneous users. The team used the search function in the Books $24 \times 7$ database to locate e-book content that sufficiently addressed the key terms and concepts and support the learner outcomes found in the course syllabus. A total of 16 titles were identified and selected to serve as the alternative core content.

Next, faculty built the course Blackboard site to include embedded e-book content. The BlackBoard site consisted of eight, two-week modules that corresponded to syllabus topics and timeline. Nicholas, et al., (2010) and Appleton (2005) note that students are more likely to embrace electronically delivered content when dipping in and out of embedded e-book links, rather than reading large portions of text. Therefore, the authors chose to embed e-book content links into the appropriate course modules in BlackBoard using persistent links and EZproxy settings to sustain on and off-campus use. Embedded links were presented to students as leading questions (i.e., "What is Marketing?") in order to provide context for the reading. This provided students with immediate and direct access to the content that answered the question versus the traditional model of reading linearly (i.e., assigned chapters 1-3).

Authors developed a pre-course survey (see Appendix B) to assess previous e-book and BlackBoard experience. The team also created eight end-of-module surveys (see Appendix C) to measure student format selection, and preference and satisfaction of course content sources, and an end-of-course survey (see Appendix D) to capture quantitative and qualitative feedback regarding the course. Survey participation was voluntary, and faculty offered extra-credit bonus points to incentivize student input. 
Authors used Qualtrics software to develop and distribute the electronic surveys. Links to each survey were available to students via a course announcement at the end of each course module. In order to administer and report on the online surveys to the students, the faculty submitted an accepted application to the university's Institutional Research Review Board.

Library and teaching faculty established a support system for students who opted to experiment using embedded e-book links. Library and teaching faculty initiated BlackBoard discussion board forums and were available by email to support students' questions and comments. Students were encouraged to contact the librarian directly if technology-related problems occurred. The librarian created instructional videos linked in the BlackBoard site to walk students through using the embedded links and the Books $24 \times 7$ database.

The authors recommend that pre-course development take place over a longer period, if possible, as this groundwork is time intensive. Table 1 . outlines the necessary steps taken by authors to build the course model before the start of fall semester 2010 .

\section{(Insert Table 1.)}

\section{Start of Course - End of Semester (16 weeks)}

During the first week of the 16-week semester, the faculty introduced the textbook alternative option to students. Students could use the traditional assigned textbook, likely purchased from the university bookstore, the embedded e-book links in their BlackBoard site paid for by the library's database subscription, or a combination of the two. Faculty assured students that both formats sufficiently covered the same course topics and that selection should not affect course grades. To reinforce the student support system set up in the BlackBoard course site, the librarian presented to 
each of the three sections methods to access e-book content and conduct course reading via the embedded links and the Books $24 \times 7$ database.

At this time, faculty administered the pre-course survey (see Appendix B). The survey gauged students' previous experience using e-books and learning management systems such as BlackBoard. Students also indicated which content source they planned to use for the semester. Sixty-seven participants completed the survey ( $77 \%$ of enrolled students). Of those 67 students, $13 \%$ indicated they would use only the traditional textbook, while $69 \%$ planned to experiment using the embedded e-book links. The remaining respondents were unsure of their choice at the time (see Table 2.).

(Insert Table 2.)

Libraries are frequently concerned about the permanency of their electronic resources, including e-books, subscribed to through aggregators and databases such as Books $24 \times 7$. To ensure that the 16 titles used in this pilot course were not pulled unexpectedly from the database, the team reached out to the vendor. The librarian submitted the 16 titles to Books $24 \times 7$ Tech Support and Product Management teams. While the vendor could not guarantee that the content would remain in the database indefinitely, they agreed to notify the authors if they intended to remove any of the titles used in the project.

End of module surveys, released approximately every two weeks, collected data to measure student satisfaction of the quality and convenience of the traditional textbook, embedded e-book links, or combination. Additionally, the surveys asked students to comment on course module layout and offer suggestions for improvement of module layout and/or content. Faculty used student feedback to implement real-time changes in subsequent modules and troubleshoot any technology problems that 
arose. Table 3. summarizes the actions taken by the authors and timeline necessary to sustain and evaluate the pilot throughout the 16-week semester.

\section{(Insert Table 3.)}

\section{End of Semester}

Before the final exam, participants completed the end-of-course survey. Sixty-nine percent of students enrolled in the three sections of the Introduction to Marketing course completed this survey (see Appendix D). This survey asked students to indicate which content source they used for the majority of the course and measured their satisfaction of the quality and convenience of that source. Responses indicate that only $4 \%$ of participants solely relied on the traditional textbook for course content. In contrast, $44 \%$ of respondents used the e-book links only and $43 \%$ relied on a combination of the two formats (see Table 4.). The authors note that these numbers reflect the end-of-course survey only and do not consider the data reported in the end of module surveys. Perhaps the most valuable measure of students' satisfaction using embedded e-book links as the core course text is the likelihood they would take a course in the future that relied solely on e-book links. Sixty-three percent of participants indicated that they were at least "somewhat likely" to take a course using this model (see Table 5.).

\section{(Insert Table 4.)}

(Insert Table 5.)

The team also conducted 13 individual and small-group student interviews to gather qualitative student feedback on the pilot course. Based on their feedback, the authors decided to redesign aspects of the BlackBoard site, such as module layouts and embedded link phrasing, and to run the pilot course again in two, spring-semester sections. Feedback from the interviews also allowed the librarian to 
tweak the training session and videos on using Books $24 \times 7$. The authors recommend that students familiarize themselves with the e-book resources before the beginning of class. Students' grasp of the technology can be measured with a simple quiz in the learning management system. Post-course student interviews and reworking of the BlackBoard site for spring semester took the authors approximately 3 weeks. Table 6 . represents a snapshot of the post-semester development period.

\section{(Insert Table 6.)}

\section{Conclusions}

While the sample size of this study is admittedly small, the reported adoption rate of e-book link use, or at least a combination of e-book link use and the traditional textbook, indicate that students are not fearful of using e-books or relying on e-books for their core course content. This result is surprising as several recent reports indicate that students still prefer print content to its electronic counterpart for course materials (Young, 2009; NACS, 2010; BISG, 2011). As shown by the end-of-course survey, 63\% of respondents indicated that they were at least "somewhat likely" to enroll in a course that offered ebook links as the singular course-content option. Moreover, given that teaching faculty reported no significant difference in grades between the pilot semester and previous iterations of the course, e-book database content from the library's collections could potentially replace traditional, assigned course textbooks without losing content quality or decreasing student learning of the course key terms and concepts.

Of course, there are limitations to this potential. The Books $24 \times 7$ e-book collections owned by the Shapiro Library are specific to the business, information technology, and finance disciplines. Equivalent content may not be available for all disciplines, therefore restricting this model's potential to certain courses. However, as evidenced by other studies, (Buczynski, 2007; Jamali, Nicholas, \& 
Rowlands, 2009; Nicholas, Rowlands, \& Jamali, 2010; Dillon, 2001), this e-book model works particularly well in the business disciplines and could be experimented with in other business courses and perhaps entire programs.

The authors believe that student satisfaction levels and willingness to experiment using e-book links as the foundational course content rely on two variables: cost and delivery. The model described in this study uses e-book content at no direct cost to the student; the material is available through an existing library subscription. This poses an additional advantage to the student over a publishermarketed electronic textbook. While the costs of e-textbooks are significantly less than their print counterparts, their use still places the financial burden on the student.

The Shapiro Library has experienced a dramatic increase in the use of its Books $24 \times 7$ e-books since the start of the pilot course in September 2010. Compared to the same time the previous year, active session minutes in the database increased $239 \%$, and individual users of the product increased 102.7\%. Vendor-supplied usage statistics allowed the authors to extrapolate this data. Tracking documented use increases is critical for effective advocacy of library funds allocated to purchase electronic library resources, especially during times of tight budget constraints (Hunter \& Bruning, 2010; Weir, 2010). The repurposing of electronic library resources for greater course integration allows students enjoy financial relief as well as increases the library's resource use and awareness.

The delivery of the e-book content as a series of embedded links in the learning management system also allowed for the success of this pilot course. Embedding the e-book content allows students to access directly the relevant content without having to read several chapters at a time. As previous studies have found, dipping in and out of content is the manner in which students successfully use e- 
books (Nicholas, et al., 2010; Christianson, M., 2005; Appleton, 2004). The initial time required to build the course BlackBoard site and embed the e-book links in each module proved time intensive for the authors. In order to ensure functionality, the authors double-checked the links several times. Moreover, the authors manually attached ez-proxy settings to each link to allow for remote access. However, once the site is built, the links are easily copied and reused from one course site to another. The faculty team reused the links in the spring semester, and all links retained functionality.

Neither the individual faculty member nor librarian had the capability or resources to offer this textbook alternative to students on their own. This model requires teaching faculty's subject expertise, open-mindedness, and desire to experiment with student learning styles. A librarian's knowledge is needed to help locate and deliver relevant content, as well as to troubleshoot technology issues and to train students on effectively and efficiently using electronic library resources. This study suggests that both librarians and teaching faculty can redefine their roles and relationships to create a positive student learning experience. While librarians and faculty frequently collaborate on projects such as collection development, information-literacy instruction, technology help, and research assistance (Horava, 2005; Pritchard, 2010; Leeder, 2011), it is not so often that librarians collaborate with faculty to influence course curriculum and delivery. This model begins to embody what Pritchard defines as embedded librarianship, where librarians are partners in curriculum design and delivery (2010). 


\section{References}

Appleton, L. (2004). The use of electronic books in midwifery education student perspective. Health Information \& Libraries Journal, 21(4), 245-252.

Appleton, L. (2005). Using electronic textbooks: promoting, placing and embedding. The Electronic Library, 23(1), 54-63.

Birnbaum, B. W. (2004, May 24). The case for online coursepacks and e-books. In Campus Technology. Retrieved from (http://campustechnology.com/articles/2004/05/the-case-for-online-coursepacks-andebooks.aspx?sc lang=en)

Buczynski, J. A. (2006). Faculty begin to replace textbooks with "freely" accessible online resources. Internet Reference Services Quarterly, 11(4), 169-179.

Christensen, E. (2010, August 17). University Book and Supply offers textbook rentals. McClatchyTribune Business News, p. 1.

Dillon, D. (2001). E-books: The University of Texas experience. Library Hi Tech, 19(4), 350-362.

Grensing-Pophal, L. (2010, April). Are Textbooks OBSOLETE? An Education in the Impact of Electronic Textbooks. EContent, 33(3), 18-22.

Horava, T. (2005). A New Approach to Faculty -- Librarian Collaboration: A "New Professors' Fund" for Collection Development. Journal of Academic Librarianship, 31(5), 482-485.

Hunter, K., \& Bruning, R. (2010). The Global Economic Crisis: What Libraries and Publishers Can Do and Are Doing. Serials Librarian, 59(2), 147-158.

Jamali, H. R., Nicholas, D., \& Rowlands, I. (2009). Scholarly e-books: the views of 16,000 academics. Aslib Proceedings: New Information Perspectives, 61(1), 33-47.

Kingsbury, A., \& Galloway, L. (2006, October 16). Textbooks enter the digital era. U.S. News \& World Report, 141(14), 63-65.

Leeder, K. (2011, July 13). Collaborating with Faculty Part 2: What Our Partnerships Look Like. In the Library with the Leadpipe. (retrieved from http://www.inthelibrarywiththeleadpipe.org).

Levine-Clark, M. (2006). Electronic Book Usage: A Survey at the University of Denver. portal: Libraries \& the Academy, 6(3), 285-299.

Nelson, M. (2008, April/May). E-books in higher education: nearing the end of the era of hype? EDUCAUSE Review, 43(2), 40-56. Retrieved from (http://www.educause.edu/EDUCAUSE+Review/EDUCAUSEReviewMagazineVolume43/EBooksinHigherE ducationNearing/162677)

Nicholas, D., Rowlands, I., \& Jamali, H. R. (2010). E-textbook use, information seeking behaviour and its impact: Case study business and management. Journal of Information Science, 36(2), 263-280. 
Pritchard, P. A. (2010). The Embedded Science Librarian: Partner in Curriculum Design and Delivery. Journal of Library Administration, 50(4), 373-396.

Shepperd, J. A., Grace, J. L., \& Koch, E. J. (2008). Evaluating the electronic textbook: Is it time to dispense with the paper text? Teaching of Psychology, 35, 2-5.

Waldman, S. (2010, July 22). A new chapter on textbook cost inflation? McClatchy - Tribune Business News.

Weir, R. O. (2010). Trimming the Library Materials Budget: Communication and Preparation as Key Elements. Serials Review, 36(3), 147-151.

Young, J.R. (2009, September 7). The Year of E-Textbooks: Many titles are available, but students are wary. The Chronicle of Higher Education. (Retrieved from http://chronicle.com/article/This-Could-Bethe-Year-of/48305/?sid=at)

Received: July 23, 2011

Accepted: August 19, 2011 
Table 1: Pre-Course Development Timeline

Pre Course (approximately 2 weeks)

- Identified necessary course content through assessing course syllabus and determined key terms and concepts vital to learner outcomes.

- Identified 16 core titles in e-book database (Books $24 \times 7$ ) that sufficiently addressed the key terms and concepts and support the learner outcomes.

- Cataloged and embedded e-book content links into appropriate course modules in LMS (BlackBoard) using persistent links and EZproxy settings to sustain off-campus use.

- Developed evaluation plan and feedback program for the semester:

- Created "Start of Course" and "End of Course" online surveys using Qualtrics software.

- Developed online surveys for distribution at the end of each course module (8 in total).

- Established direct contact between students and teaching/library faculty to create a support system.

- Initiated BlackBoard discussion board forums to support students' questions and comments.

Table 2: Student Content Source Choice, Pre-Course Survey

\begin{tabular}{|l|l|}
\hline $\begin{array}{l}\text { What source are you planning to use for the "Key } \\
\text { Terms Concepts" component of this course? }\end{array}$ & $\begin{array}{l}\text { Responses } \\
\%(n)\end{array}$ \\
\hline Traditional textbook only & $13 \%(n=9)$ \\
E-book links only & $27 \%(n=18)$ \\
Combination of textbook and e-book links & $42 \%(n=28)$ \\
Not sure & $18 \%(n=12)$ \\
Total & $100 \%(n=67)$ \\
\hline
\end{tabular}


Table 3: Semester Development Timeline

Start of Course - End of Semester (16 weeks)

- Trained students on accessing e-book content and conduct course reading through embedded links and Books 24x7 via in class training sessions and instructional videos linked in BlackBoard site.

- Librarian remained embedded in the BlackBoard course site and served as liaison to the class.

- Made contact with Books $24 \times 7$ sales and technology teams to discuss project and to ensure vendor support and reliability.

- Collected data at the end of each course module to measure student satisfaction with embedded link accessibility and content quality.

- Used feedback to implement real-time changes in the course and troubleshoot any technology problems that arose.

Table 4: Student Content Source Choice, End of Course Survey

\begin{tabular}{|l|l|}
\hline $\begin{array}{l}\text { What source are you planning to use for the "Key } \\
\text { Terms Concepts" component of this course? }\end{array}$ & $\begin{array}{l}\text { Responses } \\
\%(n)\end{array}$ \\
\hline Traditional textbook only & $7 \%(n=4)$ \\
E-book links only & $44 \%(n=27)$ \\
Combination of textbook and e-book links & $43 \%(n=26)$ \\
Not sure & $7 \%(n=4)$ \\
Total & $100 \%(n=61)$ \\
\hline
\end{tabular}


Table 5: Student Likelihood to enroll in a future course was based $100 \%$ on using e-books instead of traditional textbooks, End of Course Survey

\begin{tabular}{|l|l|}
\hline Likelihood on 7-point Scale & Responses \\
Very Unlikely =1; Very Likely = & $\%(n)$ \\
\hline & \\
Very Likely & $23 \%(n=14)$ \\
Likely & $30 \%(n=18)$ \\
Somewhat Likely & $10 \%(n=6)$ \\
Undecided & $23 \%(n=14)$ \\
Somewhat Unlikely & $2 \%(n=1)$ \\
Unlikely & $5 \%(n=3)$ \\
Very Unlikely & $7 \%(n=4)$ \\
& \\
Total & $100 \%(n=60)$ \\
& \\
\hline
\end{tabular}

Table 6: End of Semester Development Timeline

End of Semester (approximately 3 weeks)

- Solicited student feedback via individual and small group interviews

- Revamped BlackBoard site (including module layouts and embedded links) for spring semester sections of the course based on students' feedback. 


\title{
Appendix A. Timeline for Course Development
}

\author{
Timeline for Course Development \\ Pre Course (approximately 2 weeks) \\ - Identified necessary course content through assessing course syllabus and determined key terms and \\ concepts vital to learner outcomes. \\ - Identified 16 core titles in e-book database (Books $24 \times 7$ ) that sufficiently addressed the key terms and \\ concepts and support the learner outcomes. \\ - Cataloged and embedded e-book content links into appropriate course modules in LMS (BlackBoard) \\ using persistent links and EZproxy settings. \\ - Developed evaluation plan and feedback program for the semester: \\ - Created "Start of Course" and "End of Course" online surveys using Qualtrics software. \\ - Developed online surveys for distribution at the end of each course module ( 8 in total). \\ - Established direct contact between students and teaching/library faculty to create a support \\ system. \\ - Initiated BlackBoard discussion board forums to support students' questions and comments.
}

Start of Course - End of Semester (16 weeks)

- Trained students on accessing e-book content and conduct course reading through embedded links and Books 24x7 via in class training sessions and instructional videos linked in BlackBoard site.

- Librarian remained embedded in the BlackBoard course site and served as liaison to the class.

- Made contact with Books 24x7 sales and technology teams to discuss project and to ensure vendor support and reliability.

- Collected data at the end of each course module to measure student satisfaction with embedded link accessibility and content quality.

- Used feedback to implement real-time changes in the course and troubleshoot any technology problems that arose.

End of Semester

- Solicited student feedback via individual and small group interviews

- Revamped BlackBoard site (including module layouts and embedded links) for spring semester sections of the course based on students' feedback. 


\section{Appendix B. Start of Course Survey Questions}

1. Have you ever used an e-book in a course (high school or college) before?
a) Yes
b) No

2. If yes, in your opinion was using an e-book in a course setting a good experience?
a) Yes
b) No

3. What source are you planning to use for the "Key Terms and Concepts" component of this course?
a) Traditional textbook only
b) E-book links only
c) Combination of traditional textbook and e-book links
d) Not sure

4. Have you ever used BlackBoard in a course before?
a) Yes
b) No

5. Do you currently own an e-reader or an iPad?
a) Yes
b) No

6. Which of the following best describes your reason for taking this course?
a) Major/minor requirement
b) Major elective course
c) General Education
d) University elective

7. What year of school are you in?
a) Freshman
b) Sophomore
c) Junior
d) Senior
e) Graduate student

8. What is your gender?
a) Male
b) Female
c) I choose not to answer 


\section{Appendix C. End of Module Survey Questions}

1. In which section of MKT 113 Introduction to Marketing are you currently enrolled?
a. MKT 113-02100
b. MKT 113-04123
c. MKT 113-14150

\section{$\underline{\text { Textbook Source Used for Key Terms and Concepts }}$}

2. What source did you use for the "Key Terms and Concepts" component of this module?
a. Traditional textbook only
b. E-book links only
c. Combination of traditional and e-book links

\section{Used Textbook}

3. Overall, I found using the textbook convenient for this module
a. Strongly disagree
b. Disagree
c. Somewhat disagree
d. Neither agree or disagree
e. Somewhat agree
f. Agree
g. Strongly agree

Used E-Book Links

4. Overall, I found using the e-book links convenient for this module
a. Strongly disagree
b. Disagree
c. Somewhat disagree
d. Neither agree or disagree
e. Somewhat agree
f. Agree
g. Strongly agree

\section{Used Combination of Textbook and Ebook Links}

5. Overall, I found using the a combination of the textbook and e-book links convenient for this module.
a. Strongly disagree
b. Disagree
c. Somewhat disagree
d. Neither agree or disagree
e. Somewhat agree
f. Agree
g. Strongly agree 


\section{End of Module Survey}

6. I am satisfied with the quality of content covering this module's assigned "Key Terms \& Concepts."
a. Strongly disagree
b. Disagree
c. Somewhat disagree
d. Neither agree or disagree
e. Somewhat agree
f. Agree
g. Strongly agree

7. The links in this module were easy to navigate
a. Strongly disagree
b. Disagree
c. Somewhat disagree
d. Neither agree or disagree
e. Somewhat agree
f. Agree
g. Strongly agree

8. The layout of content in this module was easy to navigate.
a. Strongly disagree
b. Disagree
c. Somewhat disagree
d. Neither agree or disagree
e. Somewhat agree
f. Agree
g. Strongly agree

9. I was frustrated with the layout of the module content
a. Strongly disagree
b. Disagree
c. Somewhat disagree
d. Neither agree or disagree
e. Somewhat agree
f. Agree
g. Strongly agree

10. Do you have any suggestions for improving the content in this module (activities, links, etc.)?

11. What year of school are you in?
a) Freshman
b) Sophomore
c) Junior 
d) Senior

12. What is your gender?
a) Male
b) Female
c) I do not choose to answer 


\section{Appendix D. End of Course Survey Questions}

1. In which section of MKT 113 Introduction to Marketing are you currently enrolled?
a. MKT 113-02100
b. MKT 113-04123
c. MKT 113-14150

$\underline{\text { Textbook Source Used for Key Terms and Concepts }}$

2. What source did you use for the "Key Terms and Concepts" component of this course?
a. Traditional textbook only
b. E-book links only
c. Combination of traditional and e-book links
d. Not sure

\section{Used Textbook}

3. Overall, please indicate your level of satisfaction with the traditional textbook.
a) Very dissatisfied
b) Dissatisfied
c) Somewhat dissatisfied
d) Neutral
e) Somewhat satisfied
f) Satisfied
g) Very satisfied

\section{Used E-Book Links}

4. Overall, please indicate your level of satisfaction with the e-book links.
a) Very dissatisfied
b) Dissatisfied
c) Somewhat dissatisfied
d) Neutral
e) Somewhat satisfied
f) Satisfied
g) Very satisfied

\section{Used Combination of Textbook and E-book Links}

3. Overall, please indicate your level of satisfaction with the combination of the traditional textbook and e-book links.
a) Very dissatisfied
b) Dissatisfied
c) Somewhat dissatisfied
d) Neutral
e) Somewhat satisfied
f) Satisfied 

g) Very satisfied

5. Overall, please indicate your level of satisfaction with the course content quality
a) Very dissatisfied
b) Dissatisfied
c) Somewhat dissatisfied
d) Neutral
e) Somewhat satisfied
f) Satisfied
g) Very satisfied

6. Overall, please indicate your level of satisfaction with the course layout
a) Very dissatisfied
b) Dissatisfied
c) Somewhat dissatisfied
d) Neutral
e) Somewhat satisfied
f) Satisfied
g) Very satisfied

7. In what ways could this course be improved?

8. Would you recommend this course to other students?
a) Yes
b) No

9. If no, why not?

10. Would you take another course taught by this professor?
a) Yes
b) No
c) Maybe

11. How likely would you be to enroll in a future course that was based $100 \%$ on using e-books instead of traditional textbooks?
a) Very unlikely
b) Unlikely
c) Somewhat unlikely
d) Undecided 

e) Somewhat likely
f) Likely
g) Very likely

12. Do you currently own an e-reader or iPad?
a) Yes
b) No

13. Which of the following best describes your reason for taking this course?
a) Major/minor requirement
b) Major elective course
c) General Education
d) University elective

14. What year of school are you in?
e) Freshman
f) Sophomore
g) Junior
h) Senior
i) Graduate student

15. What is your gender?

j) Male

k) Female

l) I choose not to answer

16. What letter grade best describes your semester grade in MKT 113 Introduction to Marketing?
a) $\mathrm{A}$
b) $B$
c) $\mathrm{C}$
d) $D$
e) $E$
f) $F$
g) I do not wish to share that information 